\title{
An Unusual Cause of the Ring Artifact on Transaxial CT Images
}

Ashish Kumar Jha, Nilendu C. Purandare, and Venkatesh Rangarajan

Department of Nuclear Medicine and Molecular Imaging, Tata Memorial Hospital, Parel, Mumbai, India

Artifacts and image quality are two sides of the same coin. The ring artifact is scanner-based and caused mainly by either a miscalibrated element or a defective element of a detector row. We describe a rare cause of the ring artifact that appeared on a transaxial CT image because of a loose electronic contact. To our knowledge, this particular cause of the ring artifact has not been described in literature.

Key Words: transaxial image; artifact; computed tomography; detector module; motherboard

J Nucl Med Technol 2016; 44:214-215

DOI: 10.2967/jnmt.115.165175

\section{A}

diagnostic outcome from PET/CT imaging is the product of images that combine quality, reliability, and reproducibility. Hence, quality control testing of PET/CT equipment, both at acceptance and periodically, is mandatory to achieve the best results (1). Artifacts on CT images, though independent of PET image acquisition, can still degrade the quality of PET images during processing and interpretation (2). Non-scanner-based CT artifacts are caused mainly by improper selection of acquisition parameters and by metallic implants, patient motion, and improper patient preparation $(2,3)$. Scanner-based artifacts may appear because of a sudden breakdown of the system.

\section{CASE REPORT}

We encountered the ring artifact on a transaxial CT image while performing routine PET/CT on a 64-slice timeof-flight Gemini TF 64 scanner (Philips) (Fig. 1A, arrows). The artifact persisted on the CT scan of the uniformity phantom (Fig. 1B, arrows) and remained even after cleaning of the Mylar (DuPont Teijin Films) window with warm water. The service engineer performed the bad-detector test to rule out the possibility that the artifact was caused by

Received Aug. 5, 2015; revision accepted Sep. 8, 2015.

For correspondence contact: Ashish Kumar Jha, Department of Nuclear Medicine and Molecular Imaging, Tata Memorial Hospital, Parel, Mumbai 400012, India.

E-mail: ashish.kumar.jha.77@gmail.com

Published online Oct. 15, 2015.

COPYRIGHT (c) 2016 by the Society of Nuclear Medicine and Molecular Imaging, Inc. defective detector modules. Modules 21 and 26 did not pass the test. Two possibilities for the defect were suspected, either an electronic issue within the detector module or a loose connection between the module and the motherboard. Because the first cause would have required replacing the detector module, we tried to rule out the second cause-a loose connection. Both modules were reset in the motherboard, and the bad-detector test was repeated. This time the test did not reveal a problem with any of the modules, including 21 and 26. We then performed CT scanning of the uniformity phantom and found that the ring artifact had disappeared (Fig. 1D). We repeated the scan to confirm disappearance of the artifact. Before starting clinical imaging, we performed an air calibration test. We resumed clinical imaging after obtaining a satisfactory result from this test, and the ring artifact was not present on the clinical images (Fig. 1C).

\section{DISCUSSION}

The CT artifacts described in literature are categorized as physics-based, patient-based, or scanner-based (3). Scanner

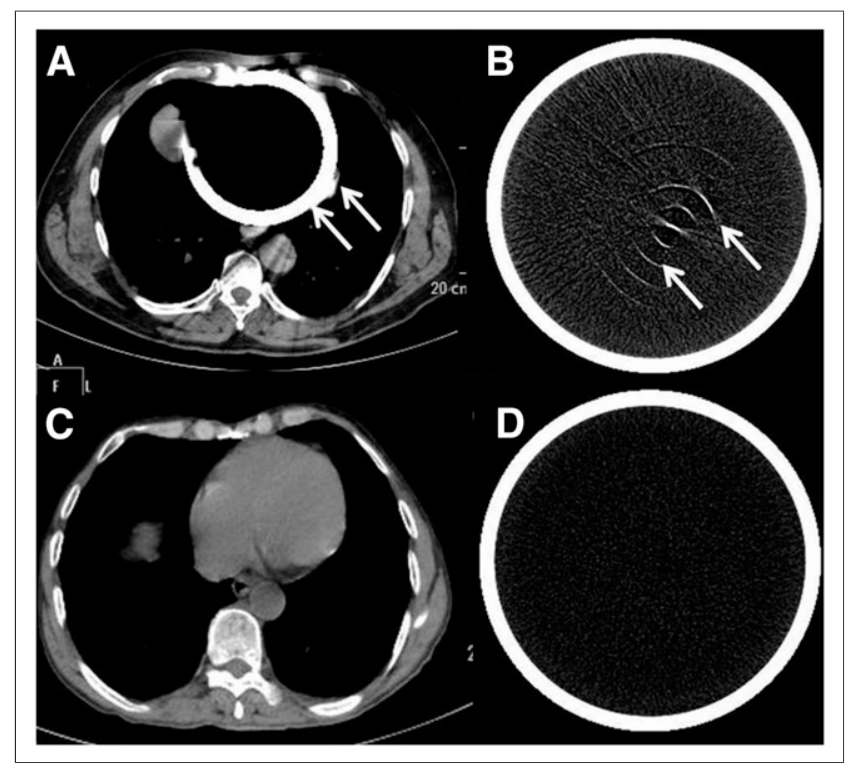

FIGURE 1. Ring artifact (arrows) present on transaxial CT image of thorax (A) and uniformity phantom (B). Disappearance of ring artifact from both thorax image (C) and phantom image (D). 
calibration and periodic maintenance by performing a series of quality control tests can help minimize scannerbased artifacts. The ring artifact- the most common scannerbased artifact-can be seen on transaxial CT images for various reasons, such as improper CT number calibration, the presence of any object during air calibration, defective detector elements, or a defective detector module $(2,3)$. Sometimes the ring artifact can appear for accidental reasons such as a contrast drop on the detector or CT tube (4). The main cause of the ring artifact is a faulty detector element, but in our case the artifact was caused by a loosening of the contact between the module and the motherboard, obstructing data flow. This is an unusual phenomenon and occurred because of compromised environmental conditions: a fluctuation in temperature, increase in humidity, and high dust load in the scanner room. The preceding week's temperature recordings for the PET/CT room showed significant temperature fluctuations to as high as $36^{\circ} \mathrm{C}$ because the air conditioner had been switched off at night. The manufacturer prescribes an ambient room temperature ranging from $19^{\circ} \mathrm{C}$ to $22^{\circ} \mathrm{C}\left( \pm 1^{\circ} \mathrm{C}\right)$ for operation of the Gemini TF 64 (5).

\section{CONCLUSION}

The ring artifact on transaxial CT images may be due to an unusual cause such as a loose electronic contact, which does not require expensive replacement of the detector module or significant downtime. This cause of the artifact can be avoided by maintaining the strict environmental conditions prescribed by the manufacturer.

\section{DISCLOSURE}

No potential conflict of interest relevant to this article was reported.

\section{REFERENCES}

1. Seeram E. Image quality. In: Computed Tomography: Physical Principles, Clinical Applications and Quality Control. 2nd ed. Philadelphia, PA: Saunders; 2001:174-199.

2. Wilting JE, Timmer J. Artefacts in spiral-CT images and their relation to pitch and subject morphology. Eur Radiol. 1999;9:316-322.

3. Barrett JF, Keat N. Artifacts in CT: recognition and avoidance. Radiographics. 2004;24:1679-1691.

4. Jha AK, Purandare NC, Shah S, Agrawal A, Puranik AD, Rangarajan V. Identification of a unique cause of ring artifact seen in computed tomography trans-axial images. Indian J Nucl Med. 2013;28:232-233.

5. Philips Medical Systems, Inc. Gemini TF and Gemini LXL system information. Release 3.5, document 459800013831, revision A, November 2009. 